\title{
Neuropsychological function in retired workers with previous long term occupational exposure to solvents
}

William E Daniell, Keith H Claypoole, Harvey Checkoway, Terri Smith-Weller, Stephen R Dager, Brenda D Townes, Linda Rosenstock

Department of Environmental Health, University of Washington, Seattle, Washington, USA W E Daniell

H Checkoway T Smith-Weller L Rosenstock

Department of Psychiatry and Behavioral Sciences, University of Washington, Seattle, WA, USA

K H Claypoole

S R Dager

B D Townes

Department of Psychology, Bogazici University, Istanbul, Turkey

B D Townes

Department of Medicine, University of Washington, Seattle, WA, USA

L Rosenstock

National Institute for Occupational Safety and Health, Washington, DC, USA L Rosenstock

Correspondence to: Dr William E Daniell, Department of Environmental Health, Box 357234, University of Washington, Seattle, WA 98195-7234, USA.

Telephone 001206685 3160; fax 206685 3990; email

bdaniell@u.washington.edu

Accepted 17 September 1998
Objectives-It is plausible that neurodegenerative processes of aging might have a
contributing role in the development of chronic effects of exposure to organic solvents. This study evaluated the risk for neuropsychological deficits among retired workers, relative to their histories of exposure to occupational solvents. Methods-This cross sectional study evaluated retired male workers, 62-74 years of age, including 89 people with previous long term occupational exposure to solvents (67 retired painters and 22 retired aerospace manufacturing workers), and 126 retired carpenters with relatively minimal previous exposure to solvents. Subjects completed a standardised neuropsychological evaluation and psychiatric interexposure and alcohol conneurological and depressive symptoms. Results-By comparison with the carpenters, the painters on average reported greater cumulative alcohol consumption and had lower scores on the WAIS-R vocabulary subtest, usually presumed to reflect premorbid intellectual functioning. These findings, however, were not sufficient to account for the other study findings. Controlling for age, education, vocabulary score, and alcohol use, the painters had lower mean scores on test measures of motor, memory, and reasoning ability; and a subgroup of aerospace workers with moderate to high cumulative exposure to solvents $(n=8)$ had lower mean scores on measures of visuomotor speed, and motor, attention, memory, and reasoning ability. Subjects were more likely to have an increased number of relatively abnormal test scores (three or more outlier scores on 17 test measures) among both the painter group (odds ratio (OR), $3.1 ; 95 \%$ confidence interval $(95 \% \mathrm{CI}) \mathbf{1 . 5}$ to 6.2) and the subgroup of aerospace workers with higher cumulative exposure (OR 5.6; 95\% CI 1.0 to 38 ). The painters, but not the aerospace workers, reported significantly more neurological and depressive symptoms.

Conclusions-The findings are consistent with residual central nervous system dysfunction from long term exposure to organic solvents, persisting years after the end of exposure.

(Occup Environ Med 1999;56:93-105)

Keywords: solvents; occupational exposure; neuropsychological tests

There is considerable evidence that long term excessive occupational exposure to mixed organic solvents can cause a wide range of chronic central nervous system abnormalities. ${ }^{1-4}$ The more severe cases of encephalopathy associated with chronic exposure to solvents are characterised by mild to moderate degrees of cognitive impairment, and are distinguished from those of other neurodegenerative diseases, such as Alzheimer's or Parkinson's disease, by the static nature of cognitive impairment and possible selective improvements in neuropsychological functioning if exposure to solvents is discontinued. ${ }^{5-7}$ Consistent with these findings, epidemiological studies of disability compensation records have repeatedly found up to a threefold risk among workers exposed to solvents for early retirement because of various neurological or psychiatric disorders, whereas studies of hospital admission records or death certificates, generally reflecting more severe disorders, typically have found less or no evidence of risk related to solvents. ${ }^{2}$ Similarly, numerous cross sectional studies comparing workers actively exposed to solvents and workers not exposed have shown relatively worse neuropsychological test performance related to exposure, particularly affecting memory, attention, perceptual or visuomotor speed, and visual spatial functioning. The findings, however, typically suggest only subclinical effects or relatively mild impairment of cognitive performance in individual subjects. ${ }^{1}$

The nature of the possible connection between long term occupational exposure to solvents, subclinical neuropsychological deficits in actively exposed worker populations, and the development of clinically evident encephalopathy in subgroups of exposed people is not clearly established. The frequency of high peak exposure to solvents with acute intoxication and the amount of cumulative exposure to solvents are reported to be major predictors of risk for chronic adverse effects of organic solvents on neuropsychological functioning. ${ }^{18}$ However, non-related factors, such as alcohol consumption, may modulate any chronic effects of exposure to solvents. ${ }^{29-13}$ 
It is plausible that neurodegenerative processes of aging might have a contributing role in the development of chronic effects of exposure to solvents, such that a neurotoxic injury related to solvents that remains subclinical during the years of exposure could manifest itself clinically in later years of life. Thus, age related neurodegeneration, in the context of residual solvent related central nervous system injury, would be more likely to exceed the threshold to develop clinically notable levels of neuropsychological impairment. If cumulative exposure to organic solvents, alcohol, and age are important interactive factors in the development of persistent neuropsychological impairment, then their effects on cognition should be most evident and identifiable in populations of older adults exposed to solvents. To investigate this possible relation between the effects of solvents and aging, the present study evaluated the risk for impairment of neuropsychological functioning in retired male workers $62-74$ years of age and compared men who had previous long term occupational exposure to solvents (retired painters and aerospace manufacturing workers) with people who had relatively minimal histories or previous exposure to organic solvents (retired carpenters).

\section{Subjects and methods}

SUBJECTS

Populations

The study populations consisted of retired painters receiving pensions from Painters' District Council 5 of the International Brotherhood of Painters and Allied Trades, and retired aerospace workers (painters and fuel cell sealers) receiving pensions from a single aircraft manufacturing company, as former active members of Aerospace Machinists Industrial District Lodge 751. The comparison population consisted of retired carpenters receiving pensions from the Carpenters' Trusts of Western Washington, as former active members of locals of the United Brotherhood of Carpenters and Joiners of America. The study procedures and supporting documents were approved by the University of Washington Human Subjects Review Committee.

\section{Eligibility}

Pension data were used to determine potential eligibility. The inclusion criteria at the time of evaluation were: $(a)$ age $62-74$ years; $(b)$ men; (c) at least 10 years cumulative work experience with routine exposure to organic solvents, or for carpenters no more than 5 years cumulative work experience with more than incidental exposure to solvents; (d) retired from the former profession for at least 1 year; and (e) current residence within a 1 hour driving distance of the study site. The aerospace worker database contained no information about experience before the mid-1960s or with other employers; those retirees were deemed tentatively eligible if they had at least 1 year of recorded service in a targeted job category, pending confirmation of longer exposure history. Because of the few women in the retired painter population $(\mathrm{n}<10)$, women were not recruited for the study.

\section{Recruitment}

All identified, potentially eligible painter $(n=189)$ and aerospace worker $(n=93)$ retirees were invited to participate. The retired carpenter population was larger, and potential participants $(n=480)$ were selected randomly within age groups $(62-65,66-69,70-74)$, to achieve a distribution comparable with the painter participants. All carpenter retirees known to have been floor finishers were invited $(n=6)$, to be included as study subjects exposed to solvents. An additional 10 retired painters, who met eligibility criteria and were inadvertently not invited to participate, initiated contact on their own and were included in the study.

Eligibility of respondents was confirmed by telephone interview and a subsequent posted questionnaire. Potential subjects were excluded from participation if any of the following criteria were met: (a) non-English primary language; (b) past or current medical problems that might cause brain injury or affect performance at the study session-for example, stroke; (c) exposure to solvents on more than an incidental basis during the 2 weeks preceding evaluation, or for more than 2 weeks cumulatively in the 6 months preceding evaluation; $(d)$ use of alcoholic beverages, drugs, or medication to the point of acute intoxication more than twice during the 2 weeks preceding evaluation, or once during the 48 hours preceding evaluation. Subjects who gave histories of alcohol use consistent with past or current alcohol misuse were not excluded. There were no exclusions from study participation on the basis of race or ethnicity.

\section{Participation}

The frequency of response to study invitations was $47 \%-52 \%$ in each of the three groups. Of respondents in each group, $24 \%-30 \%$ chose not to participate, and $11 \%-19 \%$ elected to participate but did not meet eligibility criteria; in total, $54 \%-61 \%$ of respondents participated (25\%-31\% of those approached). Based on information from the study evaluations, four studied subjects were excluded from data analysis (one industrial electrician represented by the painters' union, and three aerospace painters with only 1-2 years total career exposure to solvents). Also, 12 study participants were reclassified between study groups, including initially anticipated reclassifications: floor finishers from carpenter to painter group $(n=3)$; drywall workers from painter to carpenter group $(n=6)$; and subjects from aerospace worker to painter group based on predominant career experience and dual union membership $(n=3)$. The final sample consisted of 126 carpenters, 67 painters and 22 aerospace workers. The three participant groups showed no significant differences between the larger groups and the invited retirees in distribution of age, the only variable uniformly available for such comparison. 
Survey of non-responders

After completing recruitment efforts, samples of invited retirees who did not respond to the posted letters were contacted to ascertain reasons for non-response ( 34 painters, 55 aerospace workers, 127 carpenters selected; then $79 \%, 56 \%$, and $80 \%$ contacted, respectively). Invited retirees who responded negatively to the mailings were not surveyed, to preserve their presumed desire for privacy. A substantial proportion of surveyed non-respondents (measured only in the carpenter group: $40 \%$ ) did not recall receiving an invitation. About two thirds of the surveyed non-respondents reported being disinterested or too busy to participate (painters $63 \%$, aerospace workers $60 \%$, carpenters $72 \%) ; 4 \%-20 \%$ cited health limitations (painters $4 \%$, aerospace workers $20 \%$, carpenters $13 \%) ; 4 \%-7 \%$ were dead at the time of survey; and $11 \%-26 \%$ either were interested, thought they had responded, or had disqualified themselves because of ongoing employment (painters $26 \%$, aerospace workers $16 \%$, carpenters $11 \%$ ).

\section{METHODS}

Data collection took place from March 1990 to June 1992. Each interested, eligible respondent participated in a single 6-8 hour evaluation session. Painters were evaluated over study days 1-535 (median 150), and carpenters, days 1-724 (median 516). Aerospace workers, who were recruited later to supplement the number of formerly exposed subjects, were evaluated over study days 724-831 (median 752). Each subject received $\$ 50$ reimbursement plus a written report of his findings. Participants completed questionnaires on personal background, medical history, medication, alcohol use,${ }^{14}$ neurological symptoms, ${ }^{15}{ }^{16}$ employment history, and exposure history. A targeted physical examination emphasising cardiovascular, pulmonary, and neurological systems was conducted by examiners blinded to each subject's exposure. Blood cell counts, chemistry panel, thyroid function, and blood lead were measured to detect possible unrelated causes of central nervous system dysfunction. No subject had clinically abnormal physical examination or blood results that would warrant exclusion from the study.

\section{Structured interviews}

Each subject underwent a structured interview about past and current exposures to solvents and other hazards, and a structured interview about past and current alcohol consumption. The exposure interview was structured around each subject's employment history, focusing on periods involving one or more similar jobs; within each period subjects estimated the average proportion of work time during which direct or indirect exposure to paint or solvents occurred. Long periods of similar employment were divided into decades. For each interval with $\geqslant 10 \%$ direct exposure time, subjects estimated the average proportions of exposure time involving types of paint (oil or water based), application technique, work environment, ventilation, and personal respiratory protection. Information was collected for other activities that used solvents, exposures to other known or suspected neurotoxicants, and exposures to metals, dusts, and other chemicals. The alcohol consumption interview was structured similarly around intervals of relatively uniform drinking pattern, within which subjects answered structured questions with fixed choice answers, based on the Jessor "quantityfrequency" model. ${ }^{14}$ The self administered Michigan alcoholism screening test (MAST) also assessed drinking behaviour and possible consequences of alcohol overuse. ${ }^{17}$

\section{Neuropsychological evaluation}

Trained examiners $(n=5)$, blinded to subject exposure, administered a standard battery of neuropsychological tests, including: a verbal fluency test $^{18}$; vocabulary, similarities, block design, digit span, and digit symbol subtests of the Wechsler adult intelligence scale (WAIS-R ${ }^{19}$; Wisconsin card sorting test $(\mathrm{WCST})^{20}$; verbal aphasia screening, trails A and $\mathrm{B}$, and finger tapping tests from the Halstead-Reitan battery ${ }^{21}$; logical and visual subtests of the Wechsler memory scale-revised $\left(\right.$ WMS-R) ${ }^{22}$; Rey auditory verbal learning test ${ }^{23}$; Benton visual retention test ${ }^{24}$; 2 test $^{25}$; Stroop test $^{26}$; grooved pegboard test $^{27}$; and simple reaction time. ${ }^{28}$ Affective status was assessed by the Beck depression inventory ${ }^{29}$ and the interviewer administered, computer assisted diagnostic interview schedule (demographic, alcoholism, anxiety, depression, panic disorder, somatisation modules). ${ }^{30} 31$

\section{STATISTICAL METHODS}

All analyses were performed on personal computers with SPSS/PC+ or Epi-Info. ${ }^{32} 33$

\section{Exposure to solvents}

Indices of exposure to solvents were calculated for each person within each reported period, with a semiquantitative model adapted from Fidler et al, incorporating duration and intensity of exposure and frequency of protective factors. ${ }^{34}$ The usual amount of work time spent in activities with exposure to solvents was fractionated by the proportions of time involving specific application techniques (spraying, rolling, brushing, sealing, sealing in confined space; weighted $1.0,0.5,0.4,0.7,1.0$ respectively), and by the proportion of time spent outdoors or indoors (weighted 0.2, 1.0). Each weighted application-environment time fraction was reduced multiplicatively for time proportionate use of personal respiratory protection (none, dust mask, cartridge mask without or with adequate hygiene, air supply mask; weighted $1.0,1.0,1.0,0.5,0.1$, respectively) and ventilation (none or passive, fan or sucker, engineered exhaust system or spray booth; 1.0, $0.6,0.2$; not applicable outdoors), and then summed to yield the average annual exposure index value, constructed so as to range $0-1$. Annual values were summed or averaged to generate cumulative or average exposure indices for subjects' entire careers. 
Alcohol consumption

Alcohol consumption indices were calculated for each person within reported periods, by multiplying the frequency of alcohol consumption and the frequency weighted average quantity of drinks per sitting, with weights suggested by Jessor et al. $^{14}$

Neuropsychological tests and areas

Analyses of neuropsychological test performance were limited to white participants $(n=203)$, because strong, independent associations were found with race, and because the numbers of non-white subjects were small (5.6\% overall) and disproportionately distributed across the study groups. Two other subjects were excluded because of failure to complete testing (one carpenter, one painter), for a total of 201 subjects.

To minimise multiple testing artifacts during analysis and interpretation, and to maximise the ability to interpret findings in a readily understandable manner, neuropsychological test scores were grouped into initially determined, mutually exclusive "area" scores corresponding to major areas of neuropsychological ability (language, reasoning, memory, attention, visuomotor speed, motor function). Also, memory was subdivided into non-mutually exclusive suborea scores to reflect the dimensions of memory (visual, verbal, immediate, delayed).

To validate the assignment of neuropsychological test indices to areas and subareas, seven neuropsychologists independently ranked the degree to which each of the neuropsychological test indices reflected function in each area of ability (scale $0-4 ; 4=$ highest). All component test indices received average ranks $\geqslant 3$ for the respective areas of ability.

Distributions of neuropsychological test indices based on timed performance or number of errors were non-normal, and were logarithmically transformed for parametric statistical tests. Time and error scores, furthermore, were adjusted so that for all scores, a positive value indicated a better performance.

After standardisation of test scores (z scale, relative to raw or transformed values in the internal reference carpenter group), scores for each area and subarea were calculated for each person as the unweighted average of selected individual component test scores (two to four representative tests per area and subarea).

The significance of differences in neuropsychological functioning, between subject groups or relative to measures of exposure, was examined by analysis of covariance or multiple linear regression models, with $\mathrm{z}$ scores for individual tests and mean $\mathrm{z}$ scores for each area and subarea. Regression models included, where appropriate (stepwise entry; $p$ to enter $<0.10$; $p$ to remove $>0.25$ ): integer terms for age, years of education, and WAIS-R vocabulary score (as an index of pre-morbid intellectual ability) plus dichotomous terms for alcohol use (current or never drinking, high recent drinking, high cumulative drinking, high MAST score).
Influence of examiner

Area and individual test scores for carpenters, whose participation spanned the 2 year study period, were evaluated for possible differences between examiners or with time. Examiners 1 and 3 assessed $37 \%$ of the carpenters during the first half of the study; examiner $558 \%$, during the second half; examiners 2 and $45 \%$, at intermediate time points. Among carpenters, all individual memory tests and several other individual non-memory tests showed significant differences between examiners (each test, $p \leqslant 0.05)$ in analyses that adjusted for age, education, WAIS-R vocabulary score, and alcohol status, with each difference primarily involving examiner 5 . When only carpenters assessed by examiners 1 through 4 were considered, differences between examiners were minimal. Due to these findings, and because examiner 5 examined all aerospace workers and only five painters (7\%), analyses of scores for areas and individual tests were conducted separately (stratified) for examiners 1-4 and 5.

\section{Outlier test scores}

Scores on individual tests were categorised as outliers or not, relative to performance of the internal reference carpenter group, to denote relatively abnormal test performance. For each test, the residuals for adjusted scores (from stratified regression models) were dichotomised relative to the lower 10th percentile for the distribution of residuals in the examiner stratified carpenter group. For each participant, the outlier number was calculated as the number of individual tests on which the participant's test score fell below the 10th percentile, within each area and in total (17 test measures representing five of the six areas). Language tests were not included in calculating the total outlier number, as these tests were administered primarily as premorbid and screening measures rather than as outcome measures.

\section{Results}

DEMOGRAPHIC BACKGROUND

Distributions of age, years of education, and marital status were similar in the three subject groups (table 1). Overall, mean (SD) age was 67.9 (3.2) years, and the mean (SD) years of education was 11.1 (2.3). The proportion of non-white subjects was smaller in the painter and carpenter groups $(3 \%-5 \%)$ than in the aerospace worker group $(27 \%)$. Caffeine consumption was common but uniform among groups, median three to four drinks a day. The frequency of alcohol consumption in the preceding 6 months was similar in each group (64\%-72\%), with carpenters and painters having comparable mean rates of recent consumption, but aerospace workers, much lower. Cumulative alcohol consumption was higher among painters than carpenters, particularly among former drinkers, whereas the aerospace workers reported similar or less cumulative consumption than the carpenters. Similarly, the frequency of higher scores on the Michigan alcoholism screening test was higher among the 
Table 1 Demographic and employment background

\begin{tabular}{|c|c|c|c|c|c|c|}
\hline \multirow{2}{*}{ Age (n (\%)): } & \multicolumn{2}{|c|}{ Carpenters $(n=126)$} & \multicolumn{2}{|c|}{ Painters $(n=67)$} & \multicolumn{2}{|c|}{$\begin{array}{l}\text { Aerospace painters } \\
\text { or sealers }(n=22)\end{array}$} \\
\hline & & & & & & \\
\hline $62-65$ & 31 & $(25)$ & 19 & (28) & 6 & (27) \\
\hline $66-69$ & 52 & (41) & 25 & (37) & 11 & $(50)$ \\
\hline $70-74$ & 43 & $(34)$ & 23 & (34) & 5 & (23) \\
\hline \multicolumn{7}{|l|}{ Education (n (\%)): } \\
\hline$<12$ years & 45 & $(36)$ & 31 & $(47)$ & 9 & $(41)$ \\
\hline 12 years & 59 & $(47)$ & 27 & (41) & 9 & (41) \\
\hline$>12$ years & 22 & (17) & 8 & (12) & 4 & (18) \\
\hline Married (n (\%)) & 114 & (91) & 59 & $(88)$ & 20 & $(91)$ \\
\hline \multicolumn{7}{|l|}{ Race or ethnicity (n (\%)): } \\
\hline White & 124 & (98) & 63 & (94) & 16 & (73) \\
\hline Black & 0 & (0) & 1 & (1) & 4 & (18) \\
\hline Other & 2 & (2) & 3 & (4) & 2 & (9) \\
\hline \multicolumn{7}{|l|}{ Alcohol consumption ( $(\%))$ : } \\
\hline Recent & 88 & $(70)$ & 48 & $(72)$ & 14 & (64) \\
\hline Former (>6 months) & 30 & (24) & 18 & (27) & 7 & (32) \\
\hline Never & 8 & (6) & 1 & (1) & 1 & (5) \\
\hline Recent drinkers (median (range) drinks/day) & 0.7 & $(0.0-12.6)$ & 0.8 & $(0.0-11.0)$ & 0.1 & $(0.0-6.5)$ \\
\hline \multicolumn{7}{|l|}{ Cumulative use (median (range) drinks/day): } \\
\hline Current or recent drinkers & 42.4 & $(0.7-653)$ & 57.5 & $(0.8-688)$ & 45.5 & $(4.1-304)$ \\
\hline Former drinkers & 15.2 & $(0.0-217)$ & 84.2 & $(5.1-458)$ & 8.6 & $(0.8-172)$ \\
\hline \multicolumn{7}{|l|}{ Michigan alcoholism screening test score (n (\%)): } \\
\hline $0-1$ & 46 & $(37)$ & 14 & $(21)$ & 11 & $(50)$ \\
\hline $2-4$ & 46 & (37) & 16 & (24) & 9 & $(41)$ \\
\hline $5-7$ & 21 & (17) & 18 & (27) & 1 & (5) \\
\hline$\geqslant 8$ & 13 & $(10)$ & 19 & (28) & 1 & (5) \\
\hline Caffeinated beverage consumption (n (\%)): & 108 & $(86)$ & 57 & (85) & 19 & $(86)$ \\
\hline \multicolumn{7}{|l|}{ Employment history (median (range)): } \\
\hline Years employed as painter, floorlayer, or sealer & \multicolumn{2}{|c|}{ (see text) } & 37.0 & $(15.0-49.0)$ & 31.0 & $(9.0-41.6)$ \\
\hline Years retired & \multirow{2}{*}{\multicolumn{2}{|c|}{$[\mathrm{n}=23]$}} & \multicolumn{2}{|c|}{$5.4(1.2-14.3)$} & \multicolumn{2}{|c|}{$6.4(2.1-12.3)$} \\
\hline Solvent exposure index ${ }^{\star}$ & & & & & \multirow{2}{*}{\multicolumn{2}{|c|}{$3.77(0.20-10.6)$}} \\
\hline Cumulative & \multicolumn{2}{|c|}{$0.19(0.00-2.40)$} & \multicolumn{2}{|c|}{$3.31(0.29-13.0)$} & & \\
\hline Average & \multicolumn{2}{|c|}{$0.04(0.00-0.29)$} & \multicolumn{2}{|c|}{$0.10(0.02-0.38)$} & \multicolumn{2}{|c|}{$0.15(0.02-0.51)$} \\
\hline Blood lead concentration (median $\mu \mathrm{g} / \mathrm{dl}$ ) & \multicolumn{2}{|c|}{$6.0(0-14)$} & \multicolumn{2}{|c|}{$7.0(0-22)$} & \multicolumn{2}{|c|}{$4.0(2-17)$} \\
\hline
\end{tabular}

^Exposure index values are presented only for subjects with non-zero values. The average exposure index only reflects periods of solvent exposure.

painters, and lower among the aerospace workers compared with the carpenters.

EMPLOYMENT HISTORY

The average time since retirement was about 6 years in each group (table 1). The painters on average had spent about 6 more years in their trade than had the aerospace workers, with little overlap in occupational experience. Most of

Table 2 Symptom prevalence as reported on the questionnaire

\begin{tabular}{|c|c|c|c|}
\hline Symptoms (n (\%)) & $\begin{array}{l}\text { Carpenters } \\
(n=126)\end{array}$ & $\begin{array}{l}\text { Painters } \\
(n=67)\end{array}$ & $\begin{array}{l}\text { Aerospace } \\
\text { painters or } \\
\text { sealers }(n=22)\end{array}$ \\
\hline Tired easily & $23(18)$ & $25(37)^{\star \star}$ & $3(14)$ \\
\hline Lightheaded or dizzy & $9(7)$ & $5(7)$ & $1(5)$ \\
\hline Difficulty concentrating & $9(7)$ & $14(21)^{\star \star}$ & $2(9)$ \\
\hline Confused or disoriented & $4(3)$ & $5(7)$ & 0 \\
\hline \multicolumn{4}{|l|}{ Trouble remembering: } \\
\hline Noticed by subject & $35(28)$ & $28(42)$ & $3(14)$ \\
\hline Noticed by relatives & $14(11)$ & $18(27)^{\star}$ & $2(9)$ \\
\hline Make notes to remember & $29(23)$ & $24(36)$ & $4(18)$ \\
\hline Hard to understand reading & $6(5)$ & $10(15)^{\star}$ & $1(5)$ \\
\hline Irritable & $12(10)$ & $9(13)$ & $1(5)$ \\
\hline Depressed & $4(3)$ & $6(9)$ & 0 \\
\hline Heart palpitations & $4(3)$ & $1(1)$ & $1(5)$ \\
\hline Seizure & 0 & 0 & 0 \\
\hline Sleeping more & $9(7)$ & $12(18)^{\star}$ & $1(5)$ \\
\hline Difficulty falling asleep & $17(13)$ & $12(18)$ & $1(5)$ \\
\hline Incoordination or imbalance & $7(6)$ & $8(12)$ & $2(9)$ \\
\hline \multicolumn{4}{|l|}{ Loss of strength: } \\
\hline In legs or feet & $11(9)$ & $14(21)^{\star}$ & $4(18)$ \\
\hline In arms or hands & $10(8)$ & $10(15)$ & $4(18)$ \\
\hline Difficulty grasping & $7(6)$ & $8(12)$ & $3(14)$ \\
\hline \multicolumn{4}{|l|}{ Numbness or tingling: } \\
\hline In fingers & $11(9)$ & $5(7)$ & $2(9)$ \\
\hline In toes & $10(8)$ & $8(12)$ & 0 \\
\hline Headaches & $9(7)$ & $5(7)$ & $3(14)$ \\
\hline Difficulty driving (dizzy or tired) & $2(2)$ & $5(7)^{\star}$ & 0 \\
\hline "High" from chemicals & $3(2)$ & $11(16)^{\star}$ & $3(14)^{\star \star}$ \\
\hline Lower alcohol tolerance & $6(5)$ & $9(13)$ & $1(5)$ \\
\hline Recheck actions & $25(20)$ & $23(34)^{\star}$ & $5(23)$ \\
\hline
\end{tabular}

${ }^{\star} \mathrm{p}<0.05 ;{ }^{\star \star} \mathrm{p}<0.01 ; v$ carpenters, with logistic regression to control for age, years of education, vocabulary score, and alcohol use.

Symptoms were defined as positive when reported frequency was $\geqslant 1$ time a week. the painting experience in the painters group was in construction $(n=59,88 \%$; median 31 , range $1-46$ years), although $37 \%$ had worked as shipyard painters $(n=25$; median 5 , range $1-27$ years) and $32 \%$, as other painters $(n=22$; median 8 , range $1-43$ years; mostly maintenance painting). The three floorlayers, who were categorised with the painters, had worked in their trades for a median 42 (range 37-48) years. Other than the three subjects recategorised from the aerospace worker to the painter group, no painters had worked as an aerospace painter or sealer, and only four of 22 aerospace workers had worked as painters outside the aerospace industry (median 8, range 5-16 years). Among the aerospace workers, 14 had worked as aerospace painters (median 26, range $2-42$ years), and 11 had worked as aerospace sealers (median 29, range 2-34 years).

EXPOSURE HISTORY

The cumulative exposure to solvents index was similar on average in the painters and aerospace workers groups (table 1). However, the mean exposure index during periods of exposure to solvents was about $50 \%$ greater among aerospace workers. Cumulative exposure was greater among aerospace sealers (median 4.5, range $0.2-10.6)$ than aerospace painters (2.8, range $0.2-8.7$ ). Age showed no correlation with exposure indices or with years of exposure to paint or solvents, among painters and aerospace workers $(-0.08 \leqslant r \leqslant 0.08)$.

The carpenters group included 120 carpenters and six drywall workers, with median 36 years experience in those trades (range 15-52). Sixteen reported periods of routine but incidental painting activity (average exposure 
index $\leqslant 0.05$; for $3-10$ years, $n=10$; and for 18-38 years, $n=6$ ), and three reported heavier painting exposures for short periods (average index 0.19-0.29; for 1-3 years). Four others reported intermediate painting experience; one had the highest cumulative index for a carpenter (2.5; average 0.09 for 26 years), nearly twice that of the next highest carpenter's value.

Painters and aerospace workers were divided into three similarly sized subgroups, based on the cumulative exposure index $(<2.6$, low; 2.6 4.35 mid; $>4.35$ high); all carpenters' index values were in the low category. Because of small subject numbers, the mid and high exposure groups of aerospace workers were combined into one medium+high exposure subgroup.

BLOOD LEAD CONCENTRATIONS

The distribution of blood lead concentrations differed significantly among the three study groups ( $<<0.005$, Kruskal Wallis test), and concentrations $>10 \mu \mathrm{g} / \mathrm{dl}$ were significantly more common among painters (carpenters
$3 \%$, painters $18 \%$, aerospace workers $5 \%$; $\mathrm{p}<0.002, \chi^{2}$ test). Only two subjects, however, had concentrations as high as $20-25 \mu \mathrm{g} / \mathrm{dl}$ (two painters, each $22 \mu \mathrm{g} / \mathrm{dl}$ ). Values in the range of $10-25 \mu \mathrm{g} / \mathrm{dl}$ exceed the usual population range but generally produce no clinical manifestations in adults. ${ }^{35}$ Blood lead concentrations showed no significant association with symptoms reported or neuropsychological test performance.

SYMPTOMS

Most subjects reported no more than two positive responses to 25 symptom questions (carpenters $73 \%$, painters $51 \%$, aerospace workers $63 \%$; table 2 ). The painters, however, reported significantly more positive responses than did the carpenters (painters' median 2.0, range $0-15$; carpenters' median 1.0, range $0-14 ; p=0.001$, Mann-Whitney test), and particularly reported greater fatigue and difficulty with concentrating (each, $\mathrm{p}<0.01$ ). Dichotomising the total number of symptoms per subject as $0-2$ and $\geqslant 3$ (based on the approxi-

Table 3 Mean unadjusted neuropsychological test scores and area z scores before adjustment for potential confounding factors, without non-white subjects $(n=201)$

\begin{tabular}{|c|c|c|c|c|c|c|c|}
\hline \multirow[b]{2}{*}{ Cognitive areas and individual tests } & \multirow{2}{*}{$\begin{array}{l}\text { Direction of } \\
\text { better } \\
\text { performance }\end{array}$} & \multicolumn{6}{|c|}{ Test and area scores } \\
\hline & & \multicolumn{2}{|c|}{$\begin{array}{l}\text { Carpenters } \\
(n=123)\end{array}$} & \multicolumn{2}{|c|}{ Painters $(n=63)$} & \multicolumn{2}{|c|}{$\begin{array}{l}\text { Aerospace painters } \\
\text { or sealers }(n=15)\end{array}$} \\
\hline Language & $\uparrow$ & 0.00 & $(0.81)$ & -0.34 & $(0.86)$ & -0.03 & $(0.80)$ \\
\hline Aphasia screening (verbal errors) $\dagger$ & $\downarrow$ & 2.4 & $(2.3)$ & 3.9 & $(2.6)$ & 2.1 & $(1.8)$ \\
\hline Verbal fluency test $\dagger$ & $\uparrow$ & 41.4 & $(10.5)$ & 41.0 & $(9.9)$ & 39.5 & (11.4) \\
\hline WAIS-R vocabulary (scale score) & $\uparrow$ & 10.7 & $(2.4)$ & 9.9 & $(2.2)$ & 10.1 & $(1.5)$ \\
\hline Reasoning & $\uparrow$ & -0.01 & $(0.70)$ & -0.26 & $(0.86)$ & -0.32 & $(0.56)$ \\
\hline Trails B (time, seconds) $\dagger$ & $\downarrow$ & 107.2 & $(41.0)$ & 120.9 & $(56.7)$ & 121.2 & $(45.2)$ \\
\hline WAIS-R block design (scale score) $\dagger$ & $\uparrow$ & 12.1 & $(2.5)$ & 10.6 & $(3.1)^{\star}$ & 10.7 & $(1.8)$ \\
\hline WAIS-R similarities (scale score) $\dagger$ & $\uparrow$ & 10.9 & $(2.4)$ & 10.4 & $(2.3)$ & 10.3 & $(1.8)$ \\
\hline \multicolumn{8}{|l|}{ Wisconsin card sorting test } \\
\hline Categories completed $(<3) \ddagger$ & $\downarrow$ & 19 & $(16 \%) \ddagger$ & 9 & $(15 \%)$ & 7 & $(50 \%)^{\star}$ \\
\hline Perseverative errors $†$ & $\downarrow$ & 26.4 & $(15.7)$ & 22.6 & $(13.6)$ & 32.4 & $(22.2)$ \\
\hline Attention & $\uparrow$ & 0.00 & $(0.70)$ & -0.01 & $(0.81)$ & -0.32 & $(0.77)$ \\
\hline $\mathrm{d} 2$ test (error score) $\dagger$ & $\downarrow$ & 30.3 & $(32.3)$ & 33.6 & $(36.3)$ & 32.5 & $(46.2)$ \\
\hline \multicolumn{8}{|l|}{ Stroop test } \\
\hline Word trialt & $\uparrow$ & 85.4 & $(12.7)$ & 84.8 & $(14.6)$ & 77.8 & $(14.1)$ \\
\hline Colour-word trials & $\uparrow$ & 28.3 & $(6.8)$ & 29.4 & $(7.4)$ & 26.9 & $(4.3)$ \\
\hline WAIS-R digit span (scale score) $\dagger$ & $\uparrow$ & 9.6 & $(2.4)$ & 9.6 & $(2.3)$ & 8.7 & $(1.9)$ \\
\hline Memory & $\uparrow$ & 0.00 & $(0.69)$ & -0.11 & $(0.75)$ & -0.50 & $(0.79)$ \\
\hline Benton visual retention (errors)† & $\downarrow$ & 5.9 & $(2.8)$ & 7.2 & $(3.3)$ & 6.5 & $(2.8)$ \\
\hline \multicolumn{8}{|l|}{ Rey auditory verbal learning } \\
\hline Trials I-V & $\uparrow$ & 35.4 & $(7.8)$ & 36.8 & $(8.9)$ & 29.4 & $(5.5)^{\star}$ \\
\hline Trial VII: after interference $\dagger$ & $\uparrow$ & 6.8 & $(2.6)$ & 7.4 & $(2.7)$ & 5.1 & $(2.3)$ \\
\hline Trial VIII: delayed & $\uparrow$ & 6.3 & $(2.8)$ & 6.7 & $(2.8)$ & 4.6 & $(1.8)$ \\
\hline \multicolumn{8}{|l|}{ WMS-R logical memory } \\
\hline Immediate $\dagger$ & $\uparrow$ & 19.9 & $(6.5)$ & 20.1 & $(6.2)$ & 14.9 & $(6.4)^{\star}$ \\
\hline Delayed & $\uparrow$ & 15.6 & $(6.4)$ & 16.0 & $(7.3)$ & 13.4 & $(4.7)$ \\
\hline \multicolumn{8}{|l|}{ WMS-R visual memory } \\
\hline Immediate & $\uparrow$ & 29.0 & $(5.7)$ & 27.5 & $(6.9)^{\star}$ & 25.8 & $(7.0)$ \\
\hline Delayed $t$ & $\uparrow$ & 22.6 & $(7.6)$ & 20.3 & $(8.8)$ & 19.3 & $(8.7)$ \\
\hline Visuomotor speed & $\uparrow$ & 0.00 & $(0.78)$ & -0.10 & $(0.94)$ & -0.35 & $(0.80)$ \\
\hline $\mathrm{d} 2$ test (accuracy score) $\dagger$ & $\uparrow$ & 341.2 & $(64.4)$ & 333.9 & $(64.6)$ & 317.4 & $(52.3)$ \\
\hline Trails A (time, seconds) $†$ & $\downarrow$ & 41.8 & (14.9) & 42.4 & $(18.9)$ & 44.4 & $(16.4)$ \\
\hline WAIS-R digit symbol (scale score) $\dagger$ & $\uparrow$ & 10.3 & $(1.9)$ & 9.9 & $(2.2)$ & 9.1 & $(2.1)$ \\
\hline Motor & $\uparrow$ & 0.00 & $(0.68)$ & -0.18 & $(0.72)^{\star}$ & -0.22 & $(1.16)$ \\
\hline Finger tapping (dominant hand; taps) $\dagger$ & $\uparrow$ & 46.7 & $(5.8)$ & 46.1 & $(6.9)$ & 47.9 & $(7.8)$ \\
\hline Grooved pegboard (dominant hand; time, in seconds) $\dagger$ & $\downarrow$ & 85.7 & $(15.7)$ & 89.8 & $(19.0)$ & 98.6 & $(46.4)^{\star}$ \\
\hline Simple reaction time (seconds) $\dagger$ & $\downarrow$ & 0.294 & $4(0.047)$ & 0.301 & $1(0.053)$ & 0.307 & $7(0.033)$ \\
\hline
\end{tabular}

${ }^{\star} \mathrm{p}<0.05 \mathrm{v}$ carpenters, with multiple linear regression to control for age, years of education, WAIS-R vocabulary, and alcohol use, and stratifying by interviewers, Nos 1-4 and No 5 .

WAIS-R subtest scale scores are presented to facilitate reader interpretation, but raw scores were used in analyses.

†Tests that were used to create the respective neuropsychological area score.

¥Subjects (n (\%)). Significance of the difference between groups was determined by logistic regression, controlling for independent variables and stratifying by interviewers. Seven subjects did not complete the Wisconsin card sorting test ( 3 carpenter, 3 painters, 1 aerospace worker).

$\$$ Stroop colour word scores were not valid and are not included for 21 subjects with deficient discrimination ability of colour vision (13 carpenters, 7 painters, 1 aerospace worker). 
mate 75 th percentile among the carpenters), and with logistic regression to adjust for potential confounding factors including alcohol use, the painters were about twice as likely to report three or more symptoms (odds ratio (OR), 2.6; $95 \%$ confidence interval ( $95 \% \mathrm{CI}) 1.3$ to 5.1 ). The relative symptom excess was evident for at least nine of the 25 individual symptom questions (each $\mathrm{p}<0.05$ ). The aerospace workers reported symptoms no more often than did the carpenters (median 0.5 symptoms, range 0-7; OR 1.7; 95\% CI 0.6-4.7).

There were no substantial differences in symptom reporting (or in the background variables other than race) between the full study sample $(n=215)$ and the subsamples for whom the results of psychiatric assessment and neuropsychological testing are presented (n=199 and 201).

\section{PSYCHIATRIC ASSESSMENT}

Psychiatric interview results were available for 199 subjects. In general, there was a low prevalence of self reported current or past symptoms consistent with diagnostic criteria for psychiatric disorders other than alcohol dependence or overuse. Clinically diagnosable alcohol dependence or overuse was significantly more common among the painters $(39 \%)$ than the other study groups (each, $20 \%$; $\mathrm{p}=0.02, \chi^{2}$ test), with more alcohol use apparent both currently and historically. Nine subjects reported symptoms consistent with a generalised anxiety disorder (including four subjects with onset of symptoms in the preceding year), with no significant differences across the study groups. Only four subjects in the painter and aerospace worker groups, and none in the carpenter group, described symptoms qualifying for diagnosis of previous major depression; this association was not significant $\left(p=0.33 ; \chi^{2}\right.$ test). The painters, however, did have a significantly higher mean score on the Beck depression inventory, a measure of current depressive symptoms (carpenters' median 3.0, range $0-15$; $v$ painters' median 4.0 , range $0-29$; $\mathrm{p}=0.002$, Mann-Whitney test). This finding was not affected when Beck depression inventory scores were stratified by categories of current, former, or cumulative alcohol use. The aerospace workers showed no significant difference (median 3.0, range 0-15; p=0.99). All Beck depression inventory scores were below the range of borderline clinical depression $(17-20),{ }^{29}$ except for three painters (scores 17, 20, 29).
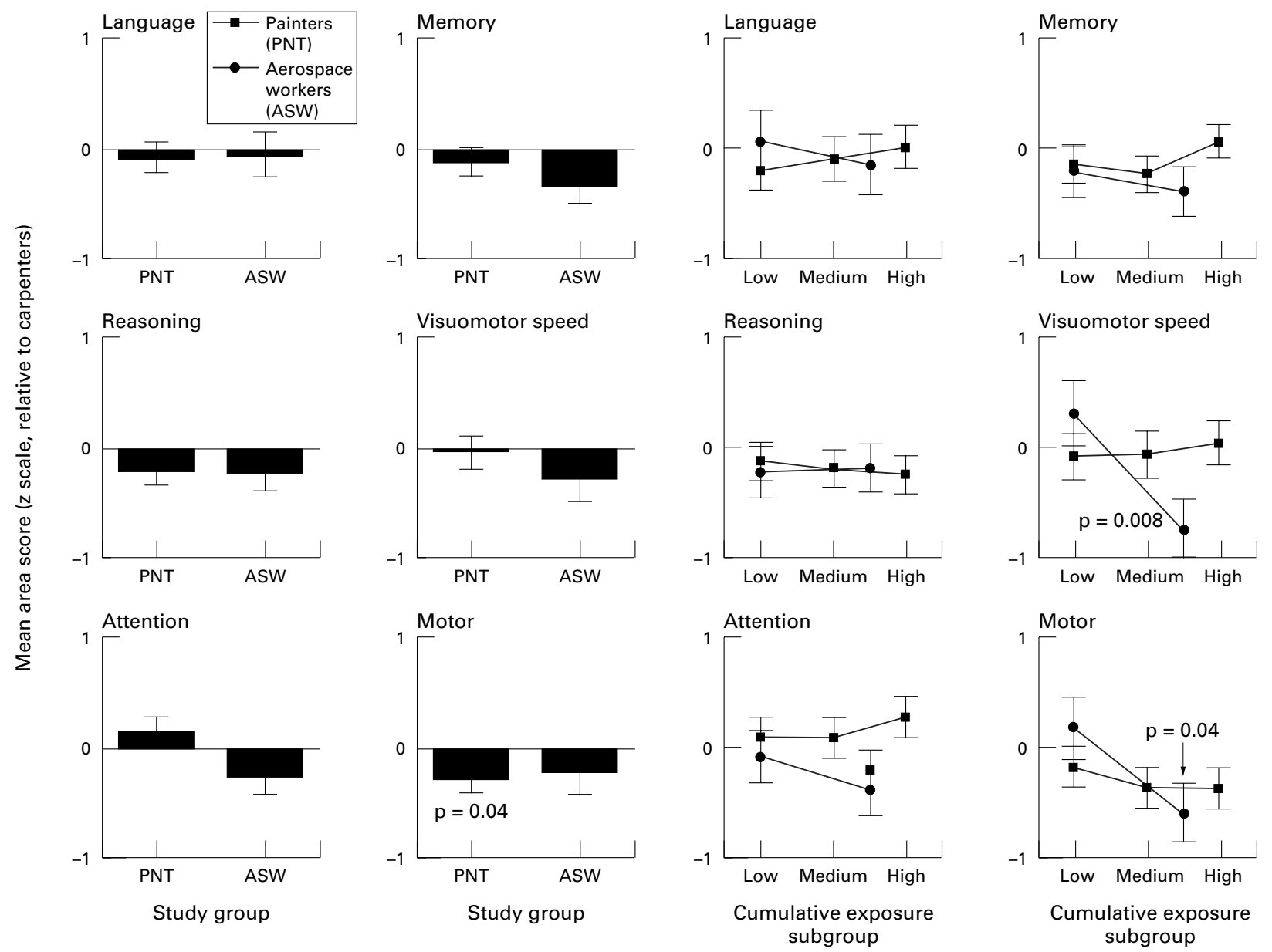

Figure 1 Mean (SEM) adjusted neuropsychological area z scores, among study groups and cumulative exposure subgroups relative to carpenters (mean $=0)$; measured in $z$ scale units; adjusting for age, years of education, WAIS-R vocabulary score, and alcohol use; and stratifying by interviewers, Nos $1-4$ and No 5. Statistical significance ( $p$ value) is printed adjacent to error bar; $p \geqslant 0.05$ if not shown. 


\section{NEUROPSYCHOLOGICAL TESTS}

Language ability

There were no significant mean differences between groups or clinical abnormalities on the tests selected to screen fundamental language ability in this older subject sample (aphasia screening, verbal fluency; table 3), after adjustment for WAIS-R vocabulary subtest score. However, the mean vocabulary score tended to be lower in the painter group than the carpenter group $(p=0.06$, analysis of covariance). Because this may not be a consistently robust measure of premorbid intellectual ability, ${ }^{36}$ analyses of scores of areas and individual tests were compared both with and without adjustment for vocabulary score.

Test scores among study groups

Mean raw scores for individual neuropsychological tests and mean area $\mathrm{z}$ scores are presented in table 3 (WAIS-R subtest scale scores are presented to facilitate reader interpretation, but raw scores were used in analyses). After stratification by examiner and adjustment for age, years of education, WAIS-R vocabulary score, and alcohol use through analysis of covariance, the painters' and aerospace workers' neuropsychological performance differed from the carpenters' with at least marginal significance on several individual tests. In the area of reasoning, the painters had significantly lower mean scores on the WAIS-R block design test $(\mathrm{p}=0.03)$, and the aerospace workers had marginally lower scores $(p=0.09)$. However, the aerospace workers, but not the painters, were significantly less likely to complete three or more categories on the Wisconsin card sorting test (OR 4.2, 95\% CI 1.2 to 14.5, $\mathrm{p}=0.02$; adjusted by logistic regression). The painters scored lower than carpenters on one test of immediate visual memory, whereas the aerospace workers scored lower on two tests reflecting immediate verbal learning and memory (each $\mathrm{p} \geqslant 0.05$ ). In the motor tests, the aerospace workers showed slower mean fine motor coordination and dexterity (grooved pegboard, $\mathrm{p}<0.05$ ), whereas the painters only showed marginally slower simple reaction times $(p=0.09)$.
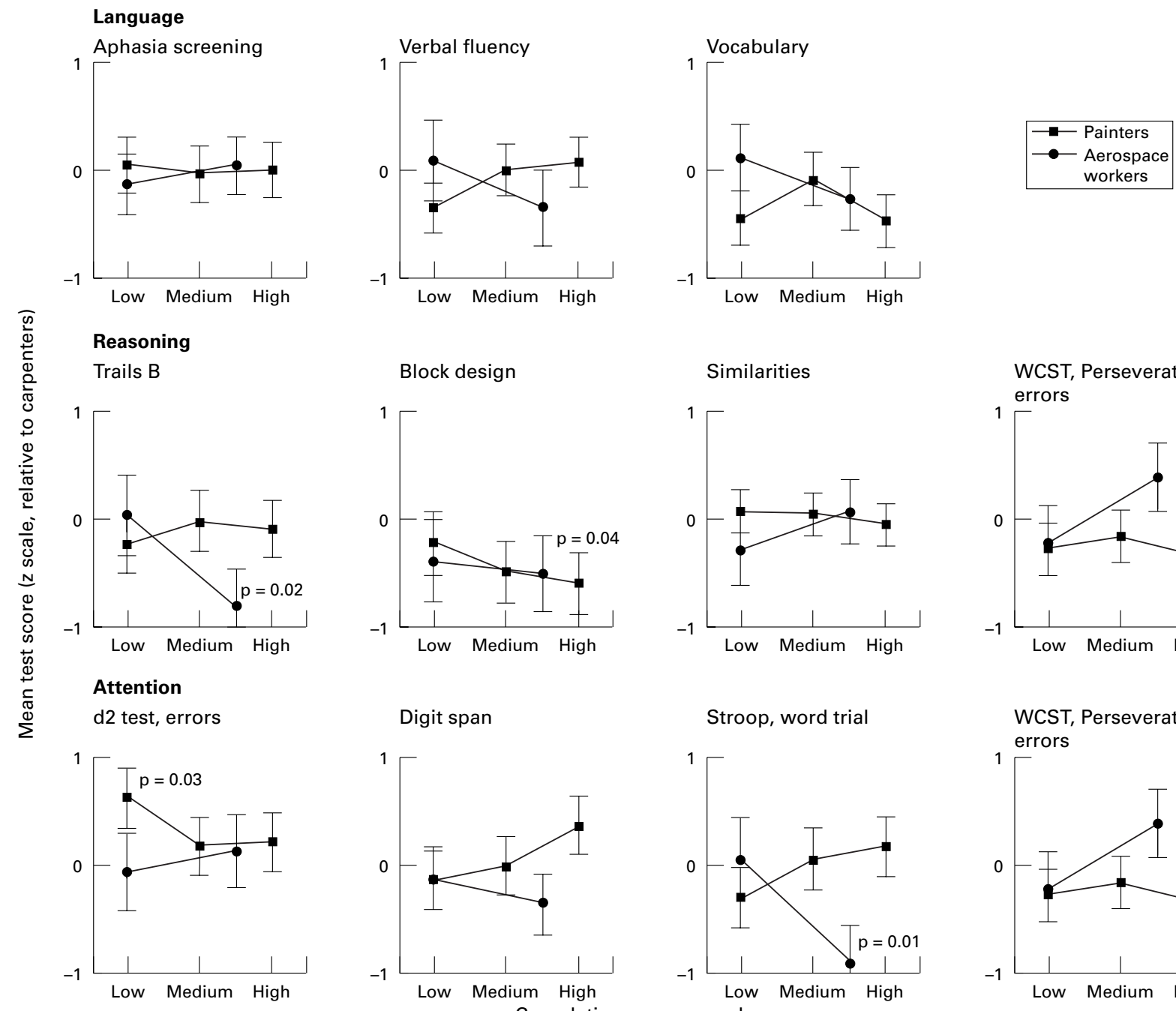

Block design
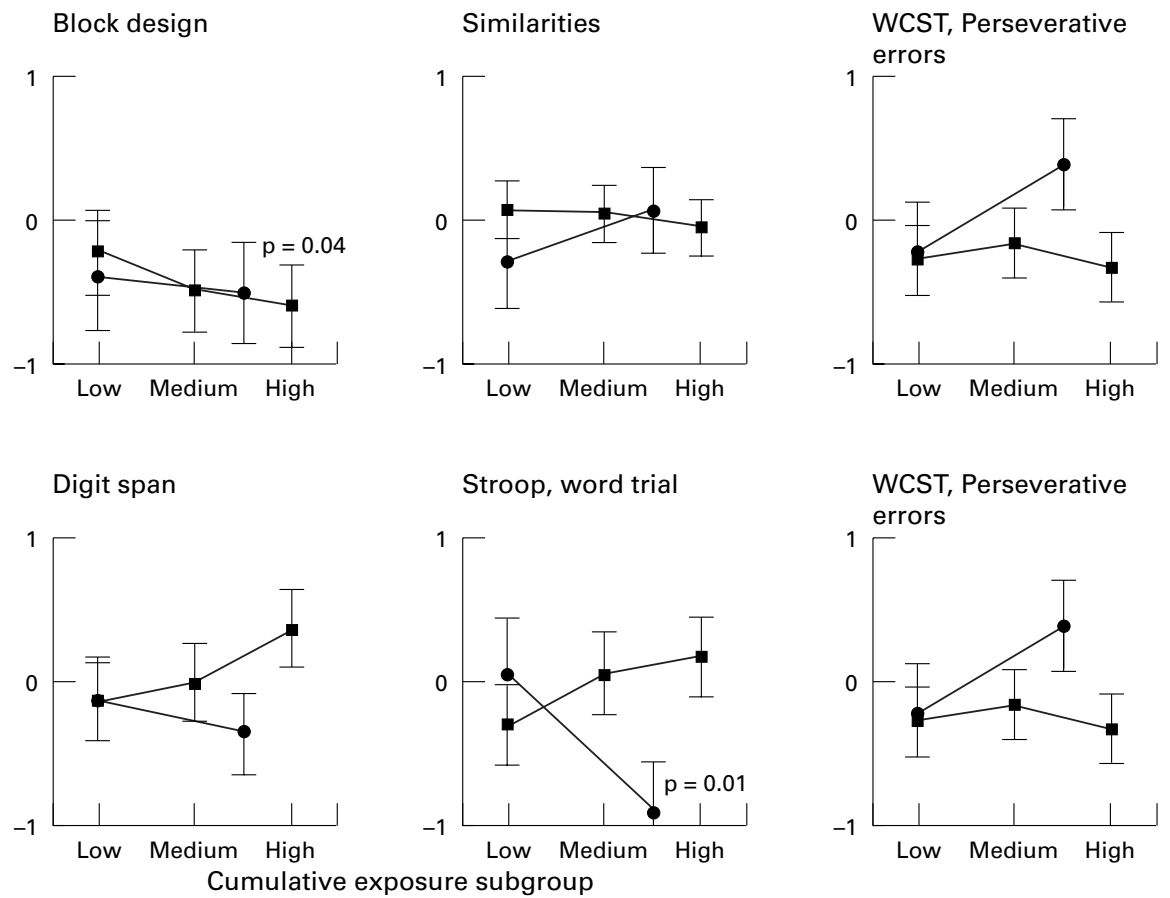

Figure 2 Group mean (SEM) values for adjusted neuropsychological test $z$ scores among cumulative exposure subgroup relative to carpenters (mean=0), measured in z scale units; adjusting for age, years of education, WAIS-R vocabulary score, and alcohol use; and stratifying by interviewers, Nos $1-4$ and No 5. Significance ( $p$ value) is printed adjacent to error bar; $p \geqslant 0.05$ if not shown. 
Area scores

When analysed at the level of tests combined within the areas of neuropsychological ability (after stratification by examiner and adjustment for age, years of education, WAIS-R vocabulary score, and alcohol use; fig 1), painters performed significantly below carpenters on the motor score $(\mathrm{p}=0.04)$ and marginally on the reasoning score $(\mathrm{p}=0.10)$. By contrast, the aerospace workers performed below the carpenters only on the memory score $(p=0.07)$, most noticeably on subarea scores for verbal memory (mean -0.34 z scale units, SD 0.16 ; $\mathrm{p}=0.03$ ) and immediate memory (mean -0.31 , SD $0.16 ; \mathrm{p}=0.06)$.
The neuropsychological area scores were examined relative to indices of mean and cumulative exposure to solvents, with multiple linear regression to test raw, log transformed, and ranked configurations of the indices, and analysis of covariance for categorised indices. The strongest associations with area scores were found with the categorised career cumulative exposure index, considered separately for the painter and aerospace worker groups (fig 1).

Compared with the carpenters, the aerospace workers with medium +high cumulative exposure had significantly lower $\mathrm{z}$ scores on two of the neuropsychological areas, visuomotor speed ( $p=0.008$; fig 1$)$ and motor abilities
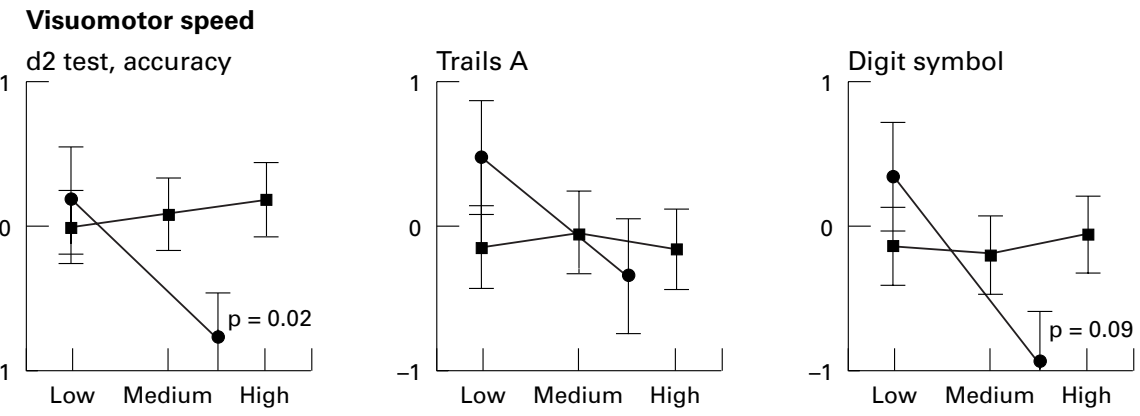

\section{Memory}
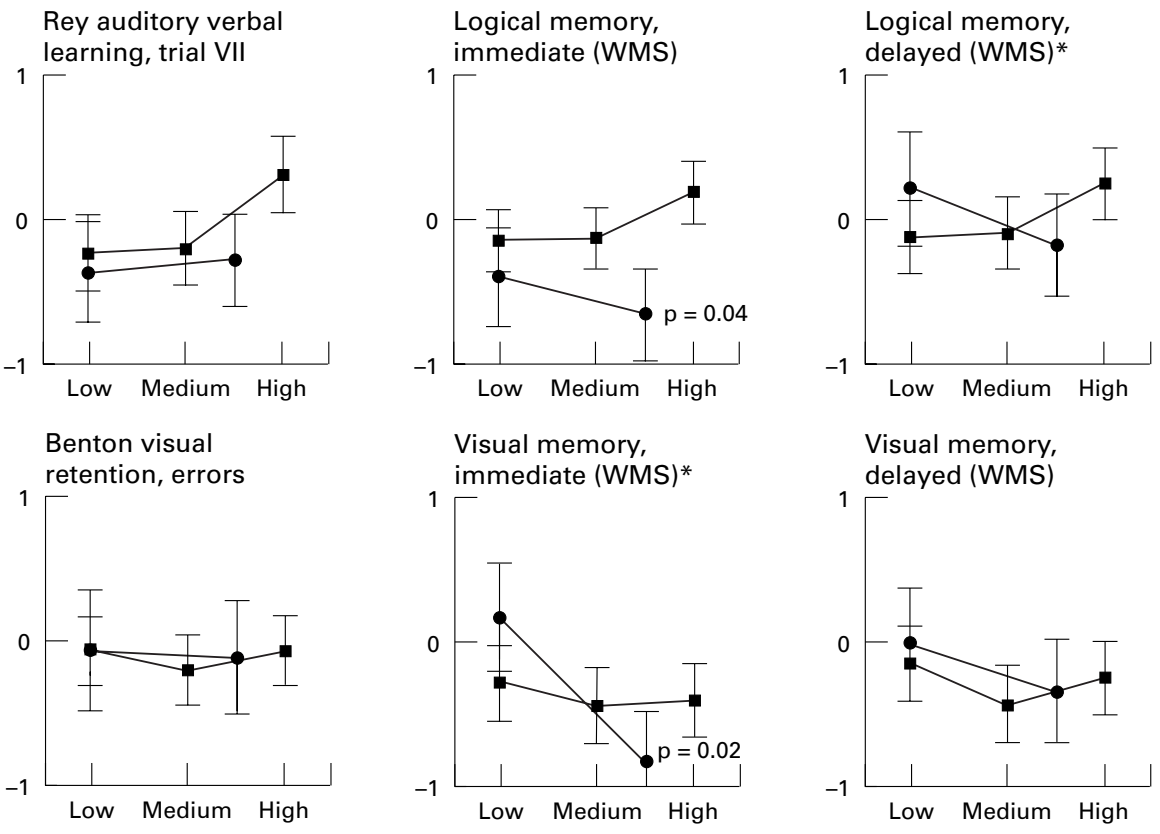

\section{Motor}
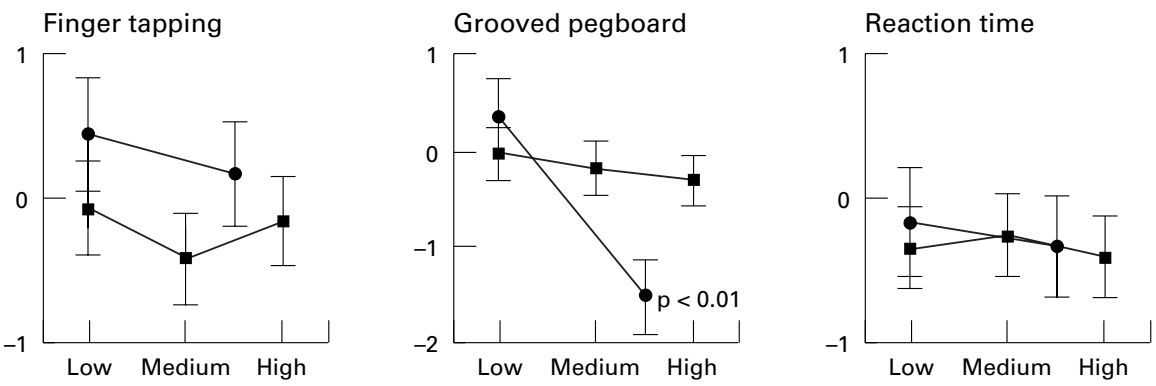

Cumulative exposure subgroup

Figure 2 (continued) 
$(\mathrm{p}=0.04)$, and marginally lower $\mathrm{z}$ scores on two others, attention and memory abilities (each, $\mathrm{p}=0.08)$. Aerospace workers with low cumulative exposure showed no differences from the carpenters on area scores. The painters, however, showed exposure related differences from the carpenters only in the motor area, where the difference in scores were marginally significant for painters with a history of mid or high cumulative exposure $(\mathrm{p}=0.08$ and $\mathrm{p}=0.06$, respectively).

Test scores and cumulative exposure in painters The association between cumulative exposure in painters and motor area performance seemed to reflect aggregate contribution by the individual tests comprising the area; cumulative exposure did not show a singular association with any one test (fig 2). Among the other areas, the painters had significantly worse scores for mean block design with increasing cumulative exposure. Otherwise, within the painter group, there were no significant exposure-response trends on individual tests. Isolated findings included significantly more errors by the painters with low exposure on the $\mathrm{d} 2$ test, and marginally lower mean scores by the painters with medium exposure on the WMS-R visual-delayed memory test $(\mathrm{p}=0.10)$.

Test scores and cumulative exposure in aerospace workers

On average, aerospace workers with medium+high cumulative exposure $(n=8)$ performed less well than did those with low exposure on all three individual tests in the area of visuomotor speed (fig 2 ), differing significantly from the carpenters on the $\mathrm{d} 2$ (accuracy score) and WAIS-R digit symbol tests. The other significantly different areas related to exposure, primarily reflected differences involving only one or two tests within each area: the Stroop word score in the attention area; grooved pegboard score in the motor area; and WMS visual immediate score in the memory area (plus the WMS-R logical immediate memory score, not a selected component of the memory area score). The Stroop colour word score, by contrast with the word score, showed no significant differences related to exposure (not shown).

Although not apparent at the level of the reasoning area score, the marginally lower trails B score for aerospace workers as a whole was

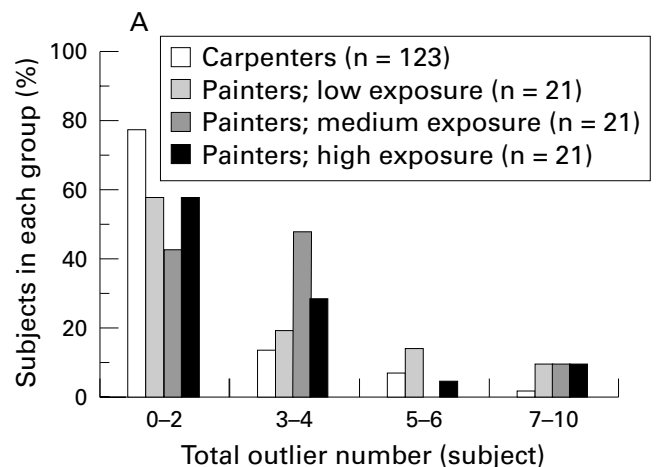

primarily attributable to subjects with medium+high cumulative exposure. Other tests of reasoning ability, however, showed no adverse association with cumulative exposure.

\section{Test scores of outliers}

The 10th percentile thresholds used to define scores as relatively abnormal outliers averaged 1.13 (SD 0.15) z scale units below the respective carpenters mean score, for the 17 test measures used to derive the total outlier number (representing the five study outcome areas, excluding language, after adjustment for the independent variables described). Considering the 17 measures in aggregate, $85 \%$ of outliers were $<1$ additional $\mathrm{z}$ scale unit below the respective threshold (median -0.37 units; 90 th percentile -1.17 units).

Most subjects had no more than two outlier scores on the 17 selected test measures (carpenters $77 \%$; painters $52 \%$; aerospace workers $67 \%$ ). On average, the painters had significantly higher total outlier numbers than the carpenters (painters' median 2.0 range $0-10$; carpenters' median 1.0 range $0-8$; $\mathrm{p}=0.02$, Mann-Whitney test), but the aerospace workers did not differ from the carpenters (median 1.0 range $0-6 ; p=0.28$ ). When the total number of outliers was analysed dichotomously ( $0-2$ and $\geqslant 3$ per subject, based roughly on the carpenters' 75 th percentile), the likelihood of a high value was increased threefold among the painters (OR 3.1; 95\% CI 1.5 to 6.2 ), and was increased to a smaller, nonsignificant degree among the aerospace workers (OR $1.7 ; 95 \%$ CI 0.4 to $6.0 ; n=15$ ), relative to the carpenters. This was less evident for the painters when other dichotomisation thresholds were used ( $\geqslant 2$ outliers OR $1.9 ; \geqslant 4$ outliers OR 1.9).

All of the aerospace workers with a high total outlier number were in the medium+high cumulative exposure subgroup (5/8), indicating a large risk related to exposure for this outcome ( $\geqslant 3$ outliers OR 5.6; 95\% CI 1.0 to 38.0 ; fig 3). By contrast, the painters showed no substantial variation in risk for an increased number of outliers relative to cumulative exposure.

Vocabulary score adjustment

When area scores were reanalysed without adjustment for WAIS-R vocabulary scores,

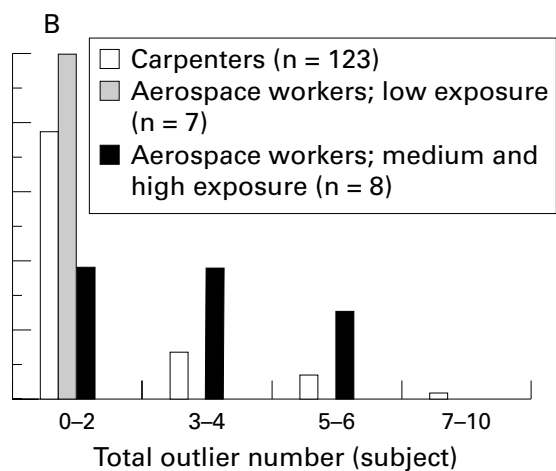

Figure 3 Subjects (\%) in each subgroup who had either 0-2, 3-4, 5-6, or 7-10 relatively abnormal outlier scores (below the 10th percentile of the carpenter group) on 17 neuropsychological test measures. 
which was used as an index of premorbid intellectual functioning, the painters' reasoning and memory scores averaged about $0.1 \mathrm{z}$ scale units lower than when analyses were adjusted for vocabulary. The mean (SD) reasoning score was $-0.21(0.14, \mathrm{p}=0.10)$ and $-0.33(0.14$, $\mathrm{p}=0.02$ ), with and without adjustment for vocabulary respectively; and the memory score, $-0.10(0.11, p=0.38)$ and $-0.21 \quad(0.12$, $p=0.10)$. The changes did not reflect a predominant effect on any one individual test. Reanalysis without adjustment for vocabulary had inconsistent effects on painters' scores relative to cumulative exposure, in most instances resulting in less evidence of doseresponse relation. Reanalysis had no substantial influence on painters' mean scores in other areas, on aerospace workers' mean area scores, or on estimates of risk for many outlier scores.

\section{Discussion}

This study found varying degrees of evidence for probable adverse effects on neuropsychological functioning associated with organic solvents among two groups of retired workers, painters and aerospace workers, with previous long term occupational exposure to solvents. It is noteworthy that, compared with a group of retired carpenters, the painters on average reported greater cumulative alcohol consumption and also had lower verbal ability on the WAIS-R vocabulary subtest, presumed to be an indicator of premorbid intellectual functioning. These potential biases, however, did not seem to account for our findings. By comparison with the neuropsychological performance of the carpenters - and while controlling for the potential confounding influences of age, education, verbal ability, and alcohol use-the painters on average had a significantly lower motor area score and a marginally lower reasoning area score, broadly assessing their performance on tests in each of those areas of neuropsychological functioning. The painters, however, had significantly lower mean scores on only two individual neuropsychological tests, each principally assessing abilities of reasoning and memory. Finally, the painters reported neurological and depressive symptoms significantly more often than the carpenters.

The smaller group of 15 aerospace workers, primarily eight subjects with moderate to high cumulative exposure to solvents, on average had significantly lower scores in the areas of motor and visuomotor speed and marginally lower area scores for attention and memory. The aerospace workers performed significantly less well on one or more individual tests in each of those areas of neuropsychological functioning, and on one individual test of reasoning ability. By contrast with the painters, reporting of symptoms by aerospace workers and carpenters did not differ.

Also, the painters and the subgroup of aerospace workers with moderate to high cumulative exposure to solvents were each significantly more likely to have an increased number of relatively abnormal neuropsychological test performances (outlier test scores), compared with the carpenters.
By contrast with the aerospace workers, there was less evidence in the painter group that greater amounts of cumulative exposure were associated with relatively lower neuropsychological test performance, other than on the WAIS-R block design subtest and on the motor area score, although this was not evident at the level of individual tests of motor functioning.

There was no evidence that alcohol influenced or mitigated any long term effects of organic solvents on reporting symptoms or neuropsychological functioning in this study sample. The painters as a group reported much greater cumulative alcohol consumption than the aerospace workers or carpenters, but showed no more evidence of possible effects of solvents than the aerospace workers, and in many analyses showed less evidence. None the less, the painters' higher reported alcohol consumption is striking and may represent a risk for health problems related to alcohol overuse or alcoholism.

The findings of the present study are consistent with those of two retrospective cohort studies, in Denmark and in Sweden, that evaluated painters with long term exposure to solvents and included pre-exposure psychometric data from the subjects' testing at the time of military conscription. ${ }^{37}{ }^{38}$ The subjects' average age in each study was about 50 years (Danish study, mean 53; Swedish study, median 50). Both studies found few differences between painters and comparison groups when performance on individual neuropsychological tests was analysed numerically, comparing group mean values. The Swedish study found no interactive effect of exposure to solvents and alcohol consumption on central nervous system function, but by contrast with the present study, found no differences in reported alcohol use associated with exposure. ${ }^{38}$ The Danish study further found that the odds ratios for mild or greater degrees of dementia, as judged by a psychologist, were 3.6 and 5.0 for painters with medium and high exposure to solvents, respectively, compared with bricklayers; however, the association did not predominantly involve any one area of neuropsychological functioning. ${ }^{37}$ This is analogous to the approach and findings in the present study, which examined the number of outlier or relatively abnormal neuropsychological test scores, as defined internally relative to the 10 th percentile of performance in the carpenters' group. The present study found up to a fivefold increased risk for having a relatively high number of outlier test scores, among subjects with greater degrees of previous exposure to solvents.

The findings of the two Scandinavian studies and the present study affirm the methodological need for studies to examine the relative frequency of outlier or clinically abnormal test performance and to examine scores in a global manner. The analysis of outlier or abnormal test performance may augment the ability of a study to detect phenomena associated with exposure for which an exposed group is broadly at risk. It also may increase the 
feasibility of detecting phenomena that place only a subgroup of exposed people at risk, conceivably due to heterogeneity of people's genetic or constitutional susceptibility to adverse effects on the central nervous system of exposure to organic solvents.

Consistent with most previous studies that used comprehensive neuropsychological evaluation, this study found minimal evidence that previous exposure to solvents differentially affects selected aspects of neuropsychological function more than others. This study found that aerospace workers with moderate to high cumulative exposure to solvents had relatively lower mean test scores across most tested neuropsychological areas, with relatively worse performance in memory and learning, and with relative sparing of more complex reasoning abilities. The painters, however, even those with moderate or high exposure, showed relatively less difference than did the aerospace workers, in mean test score comparisons with the carpenters. Also, the differences in outlier test scores related to exposure were most obvious globally, by the number of outlier test scores in total rather than within neuropsychological areas.

The ability to interpret the findings of this study or generalise its findings to other exposed people, is potentially limited by features of the study design and sample selection. The cross sectional study design may have failed to identify members of the populations of truely exposed and comparison workers, including people who migrated out of the trade before eligibility for a pension, particularly those leaving the trade due to adverse effects of solvents, and people who were eligible but did not file for a pension or died before receiving a pension. There were deficiencies in the ability of the painters pension fund to accurately identify all eligible painters; some retirees receiving pensions were identified only by inquiry by a volunteer.

The low ratios of response $(47 \%-51 \%)$, interest $(34 \%-38 \%)$, and eligibility for participation $(25 \%-31 \%)$ by invited retirees are of particular concern in this study. The two mentioned Scandinavian studies used similar recruitment approaches and achieved remarkably higher participation ratios, $60 \%-90 \%$, in their different subject groups. ${ }^{37}{ }^{38}$ Fortunately, in the present study the recruitment statistics and the findings of the non-respondent survey were reasonably uniform across the three study groups, and distribution of the one variable available for comparison, age, was similar in each of the subject groups and respective populations. However, despite the problems with subject recruitment, the findings of the present study do generally agree with those of the two Scandinavian studies, showing a pattern of relatively mild to moderate but diffuse decline in neuropsychological functioning.

Another concern is examiner or temporal bias. Subjects for this study were recruited over a long period, with painters generally being examined earlier in the study period, aerospace workers later, and carpenters throughout. Neuropsychological tests were administered by a single examiner during the final portion of the study period, including all aerospace workers and about half of the carpenters. Despite study procedures to control quality of test administration, analysis of carpenter scores showed significant differences between examiners on several tests, most evidently associated with the final examiner. The differences presumably reflect either a true examiner bias or an unrecognised associated temporal phenomenon. The analysis of the scores of subjects tested by this examiner separately from those tested by the other examiners, should effectively control this confounding influence, although with the loss of some statistical power. However, it is conceivable that this approach might not have been completely effective. At least, this occurrence emphasises the need to consider the possible influence of examiner bias in studies of neuropsychological functioning, despite seemingly appropriate study procedures for quality control.

It is not clear why the present study found dose related adverse associations between exposure to organic solvents and performance on many individual neuropsychological tests in the small group of aerospace workers but only on one test in the painters' group. One credible explanation is the qualitative difference in types of paints and solvents used in aerospace manufacturing, compared with painting in construction, shipbuilding, and other settings. The exposure index had no ability to assess differences in the numerous, diverse, and often unknown chemical ingredients of the solvent or paint agents. Also, the exposure index was based entirely on subjective recall, and it is conceivable that the painters, who generally had more complex employment histories than the aerospace workers, were less able to accurately recount their exposure histories. Quantitatively, the painters and aerospace workers had similar distributions of cumulative exposure index values, and the exposures of most subjects in these two groups should have exceeded any no effect level, as characterised in the review by Mikkelsen et al. ${ }^{37}$ The painters and aerospace workers, however, did have different temporal patterns of exposure, with the aerospace workers generally showing slightly higher average exposures across shorter career spans and even higher exposures during certain periods. It is possible that these reflected differences not just in degree but also in the frequency of high, acutely intoxicating exposures, which in theory could be associated with greater long term or cumulative risk of central nervous system injury than would more uniform exposures. Finally, it is conceivable that the previous exposures of some carpenters to low concentrations of solvents or over short periods, and their possible exposures to other neurotoxicants such as lead, could have weakened the ability of the study to detect effects related to solvents in the groups of painters or aerospace workers.

In conclusion, the findings of this study are consistent with residual effects on central nervous system function from long term occupational exposure to solvents, persisting long 
after the end of exposure, and appearing as a severalfold increased risk for relatively abnormal neuropsychological function. The magnitudes of risk in this study sample are similar to those found in two retrospective cohort studies of career painters, who on average were 15 years younger than those in the present study. Given the limited age range of the subjects in the present study (62-74), this study has little ability to assess directly whether there exists any interactive contribution to chronic solvent neurotoxicity by age related neurodegeneration. However, the evidence of a relative risk related to solvents that persists years after the end of exposure, and that persists into years of life when age related neurodegeneration is increasingly prevalent in the general population, suggests that career long exposure to solvents could have greater clinical importance in later years of life than during the years of active exposure. A study with a longitudinal rather than cross sectional design could examine the issue of an interaction between age and solvents in a more direct manner but would be logistically challenging to conduct. Finally, given the small size of the group of aerospace workers, it is not possible to conclude that workers with exposures similar to those of the studied population are at greater risk of neurotoxicity related to solvents than are painters in other industries. A study that includes many more aerospace painters and sealers would be necessary to make definitive assessments about health risks in those trades.

Funds for this study were provided by the United States National Institute for Occupational Safety and Health, grant number R01-OH02683. BDT received a Fulbright fellowship.

1 Mikkelson S, Jorgensen M, Browne E, et al. Comparison with the findings of similar studies (chapter 9). Cited in: Mixed solvent exposure and organic brain damage; a study of painters. Acta Neurol Scand 1988;118(suppl 118):79-93.

2 Hogstedt C. Has the Scandinavian solvent syndrome controversy been solved? Scand 7 Work Environ Health 1994;20(suppl):59-64.

3 Baker EL. A review of recent research on health effects of human occupational exposure to organic solvents. f Occup Med 1994;36:1079-92.

4 White RF, Proctor SP. Solvents and neurotoxicity. Lancet 1997;349:1239-43.

5 Gregersen P, Klausen H, Elsnab CU. Chronic toxic encephalopathy in solvent-exposed painters in Denmark encephalopathy in solvent-exposed painters in Denmark 1976-80: clinical cases and social consequences

6 Svensson BG. Long term follow up of workers exposed to Svensson BG. Long term follow up of
solvents. Br f Ind Med 1990;47:75-82.

7 Orbaek P, Lindgren M. Prospective clinical and psychometric investigation of patients with chronic toxic encephalopathy induced by solvents. Scand $\mathcal{F}$ Work Environ Health 1988 14:37-44.

8 Flodin U, Edling C, Axelson O. Clinical studies of psychoorganic syndromes among workers with exposure to solvents. Am f Ind Med 1984;5:287-95.

9 Morrow LA, Ryan CM, Hodgson MJ, et al. Risk factors associated with persistence of neuropsychological deficits in persons with organic solvent exposure. 7 Nerv Ment Dis 1991;179:540-5.
10 Lundberg I, Gustavsson A, Hogberg M, et al. Diagnoses of alcohol abuse and other neuropsychiatric disorders among house painters compared with house carpenters. $\mathrm{Br} \mathcal{F}$ Ind Med 1992;49:409-15.

11 Guberan E, Usel M, Raymond L, et al. Disability, mortality, and incidence of cancer among Geneva painters and electricians: a historical prospective study. $\mathrm{Br} \mathcal{F}$ Ind $\mathrm{Med}$ 1989;46:16-23.

12 Cherry N. Neurobehavioural effects of solvents: the role of alcohol. Environ Res 1993;62:155-8.

13 Cherry N, Labreche F, McDonald C. Organic brain damage and occupational solvent exposure. $\mathrm{Br} \mathcal{F}$ Ind Med 1992;49: $776-81$.

14 Jessor R, Graves TD, Hanson RC, et al. Society, personality and deviant behavior. New York: Holt, Rinehart, and Winston, 1968

15 Hogstedt C, Andersson K, Hane M. A questionnaire approach to the monitoring of early disturbances in central nervous functions. In: Aitio A, Riihimati V, Vainio $\mathrm{H}$, eds: Biological monitoring and surveillance of workers exposed to
chemicals. Washington: Hemisphere, 1984 .

6 Letz R, Baker EL. Neurobehavioral evaluation system (NES) user's manual, version 3.11. Boston: Harvard School of Public Health, 1985

17 Selzer ML. The Michigan alcoholism screening test: the quest for a new diagnostic instrument. Am $\mathcal{F}$ Psychiatry 1971;127:1653-8

18 Spreen O, Strauss E. A compendium of neuropsychological tests. Administration, norms and commentary. New York: Oxford University Press, 1991.

19 Wechsler D. Wechsler adult intelligence scale-revised. San Antonio, TX: The Psychological Corporation; Harcourt, Brace, Jovanich, 1981.

20 Berg EA. A simple objective test for measuring flexibility in thinking. $\mathcal{F}$ Gen Psychol 1948;39:15-22.

21 Halstead WC. Brain and intelligence. Chicago: University of Chicago Press, 1947.

22 Wechsler D. Wechsler memory scale-revised. San Antonio, TX: The Psychological Corporation; Harcourt, Brace, Jovanich, 1987.

23 Rey A. L'Examen Clinique en Psychologie. Paris: Presses Universitaires de France, 1964

24 Benton AL. The revised visual retention test, 4 th ed. New York: The Psychological Corporation; Harcourt, Brace, Jovanich, 1974.

25 Spreen O, Strauss E. Concentration endurance test. In: $A$ compendium of neuropsychological tests: administration, norms, and commentary. NY: Oxford University Press, 1991:138142.

26 Stroop Jr. Studies of interference in serial verbal reactions. $\mathcal{f}$ Exp Psychol 1935;18:45-48.

27 Matthews CG, Klove H. Instruction manual for the adult neuropsychology test. Madison: University of Wisconsin Medical School Press, 1964.

28 Johnson BL, ed. Prevention of neurotoxic illness in working populations. New York: John Wiley, 1987.

29 Beck AT, Ward CH, Mendelson M, et al. An inventory for measuring depression. Arch Gen Psychiatry 1961;4:561-71.

30 Singerman B, Stoltzman RK, Stoltzman RK, et al. Diagnostic concordance between DSM-III, Feighner, and RDC. $\mathcal{F}$ Clin Psychiatry 1981;42:422-6.

31 Walker EA. UW-DIS: DIS version III-A; DSM-III-R diagnoses, version 87.12. Seattle, WA: University of Washington, 1989 .

32 Norusis MJ. SPSS/PC+ version 4.01 for the IBM/PC/XT/AT and PS/2. Chicago: SPSS, 1990

33 Centers for Disease Control. Epidemiology program. Epi-Info, version 6. Atlanta, GA: CDC, 1994.

34 Fidler A, Baker EL, Letz RE. Estimation of long-term exposure to mixed solvents from questionnaire data: a tool for epidemiological investigations. Br f Ind Med 1987;44:13341 .

35 Landrigan PJ, Todd AC. Lead poisoning. West f Med 1994; 161:153-9.

36 Michelsen H, Lundberg I. Neurospychological verbal tests may lack hold properties in occupational studies of neurotoxic effects. Occup Environ Med 1996;53:478-83.

37 Mikkelson S, Jorgensen M, Browne E, et al. Mixed solvent exposure and organic brain damage; a study of painters. Acta Neurol Scand 1988;118(suppl 118):1-143.

38 Lundberg I, Michelsen H, Nise G, et al. Neuropsychiatric function of housepainters with previous long-term heavy exposure to organic solvents. Scand $\mathcal{F}$ Work Environ Health 1995;21(suppl 1):1-44. 